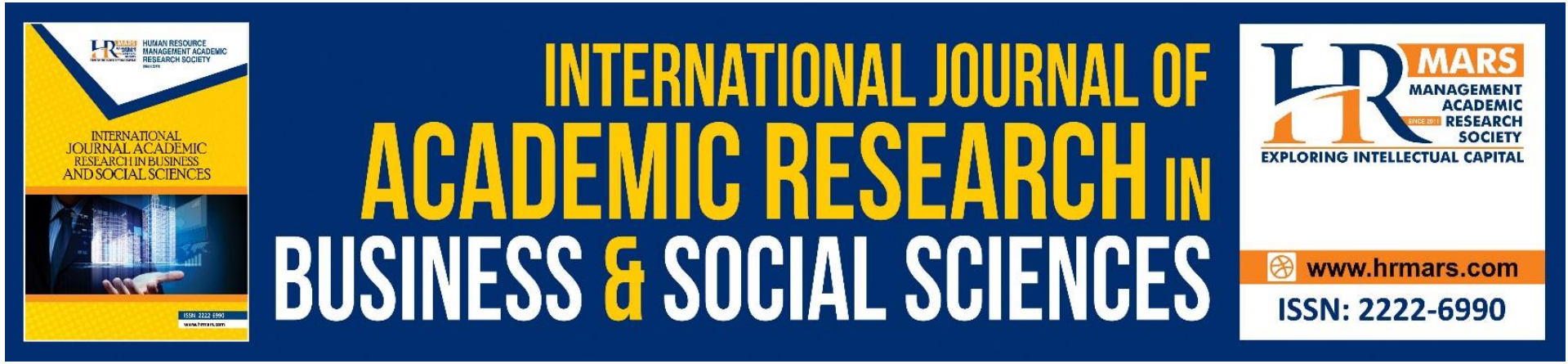

\title{
Improving Lower Primary Students' Vocabulary Retention Through Interactive Storyboard Game (ISG)
}

\section{Elizabeth Su Xin-Li, Michelle Ting Lik Chiew, Melor Md Yunus}

To Link this Article: http://dx.doi.org/10.6007/IJARBSS/v11-i6/10056

DOI:10.6007/IJARBSS/v11-i6/10056

Received: 14 April 2021, Revised: 18 May 2021, Accepted: 03 June 2021

Published Online: 21 June 2021

In-Text Citation: (Xin-Li et al., 2021)

To Cite this Article: Su, E. X. L., Ting, M. L. C., \& Yunus, M. M. (2021). Improving Lower Primary Students' Vocabulary Retention Through Interactive Storyboard Game (ISG). International Journal of Academic Research in Business and Social Sciences, 11(6), 1514-1526.

\section{Copyright: (c) 2021 The Author(s)}

Published by Human Resource Management Academic Research Society (www.hrmars.com) This article is published under the Creative Commons Attribution (CC BY 4.0) license. Anyone may reproduce, distribute, translate and create derivative works of this article (for both commercial and non-commercial purposes), subject to full attribution to the original publication and authors. The full terms of this license may be seen at: http://creativecommons.org/licences/by/4.0/legalcode

Vol. 11, No. 6, 2021, Pg. 1514 - 1526

Full Terms \& Conditions of access and use can be found at http://hrmars.com/index.php/pages/detail/publication-ethics 


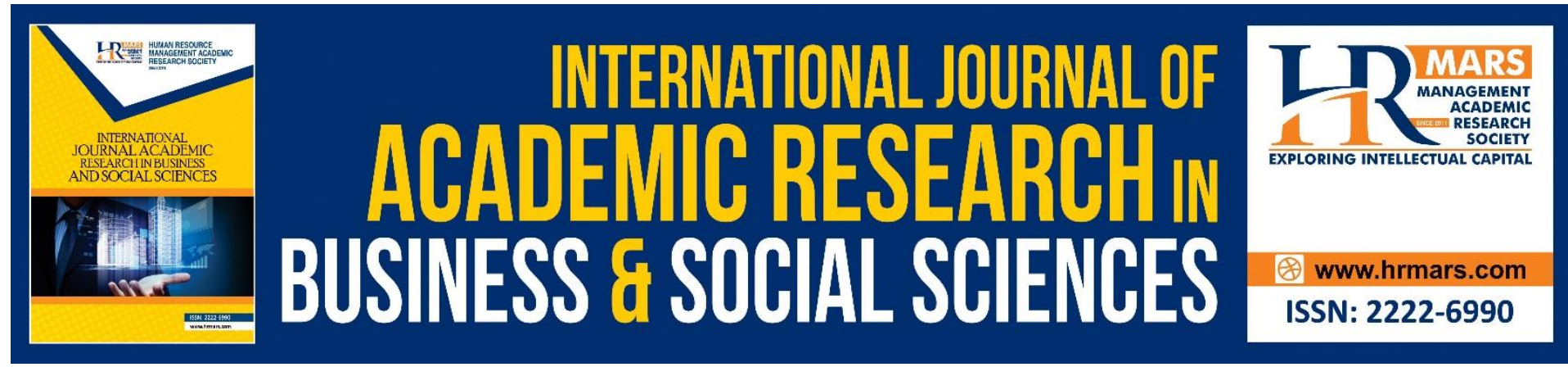

\title{
Improving Lower Primary Students' Vocabulary Retention Through Interactive Storyboard Game (ISG)
}

\author{
Elizabeth Su Xin-Li ${ }^{1,3}$, Michelle Ting Lik Chiew²,3, Melor Md \\ Yunus $^{3}$ \\ ${ }^{1}$ SJK (C) Chuang Hua Sungai Moyan, 93250, Padawan, Sarawak, ${ }^{2}$ SJK (C) San San, 96300, \\ Dalat, Sarawak, ${ }^{3}$ Faculty of Education, Universiti Kebangsaan Malaysia \\ Email: elizabeth.su.92@gmail.com, zerodistance.chiew137@gmail.com, \\ melor@ukm.edu.my
}

\begin{abstract}
The current CEFR-aligned Year 1 English syllabus is taught in the British context as the main material in use is the Superminds Student's Book and Workbook printed by Cambridge University Press. As such, many of the terminology employed in the book are taught in a setting where students do not experience them and are unable to recognise and associate word meanings along with contextual learning purposes. This study is significant as it provides educators facing the same issue with a possible solution in overcoming the issue, which is crucial in learning a second language, especially as English is seen as an international language. The action research model was used in this study as it allowed the researchers to identify the issue, plan an action, implement the action, and review the effectiveness, followed by making adjustments and carrying out a second round of intervention if necessary. The data was collected from twenty five (25) Year 1 students as respondents. This action research used pre-test and post-test as well as observations as instruments to collect data. Findings from this study found that ISG was effective for a large number of participants in the study. Future research can focus on the implementation of the same method on weak learners at a higher level to explore if the method is truly able to help them improve their vocabulary retention. Furthermore, future research can also target a larger number of participants and implement and experimental research design to increase the reliability and validity of the data obtained.
\end{abstract}

Keywords: Vocabulary Retention, Interactive Game, Lower Primary, English, Educational Games

\section{Introduction}

Vocabulary is an important aspect of language learning as it determines whether or not learners would be successful in acquiring the language. Thornbury (2002) said that the lack of grammar will impede the ability to be understood, while the lack of vocabulary will cause the speaker/writer to not be understood. Despite being such a crucial skill for learners, 
Yunus, Lau, Hartini and Yusof (2020) claim that the majority of young learners, aged 7 to 12, have poor vocabulary acquisition in spite of early exposure to the target language.

One of the biggest problems encountered by second language learners that aroused the raising concern is the pupils' poor recall of vocabulary. Many of the pupils were mostly unable to recall the vocabulary let alone the associated meanings they had acquired from one day to the next. This has indeed fired whistleblowers among the teachers as if the effort of teaching vocabulary does not get to be established and go into the drain. For instance, if the teacher taught pupils three new words on a day, they would forget two of the words the next day. The problem is not that the pupils are absent-minded but humbled by the fact that there have been pupils who can recognise the written or oral form of the word, but could not generate the word meanings without the guidance of the teachers. In fact, the low level of vocabulary of the pupils continued to be a significant stumbling block throughout reading and writing lessons. Therefore, several claims have been made that vocabulary retention is indeed a crucial part during vocabulary learning.

As students are accustomed to conventional teaching methods, and more often than not, they tend to memorise the new vocabulary through rote memorisation which is based on repetition, and this could result in condensed and shorter attention when acquiring vocabulary. Likewise, most current syllabuses and curriculum concentrate only on introducing new vocabulary to the students but they fail to determine whether the learnt vocabulary is retained by the students or the contrary. In fact, merely exposing students to new vocabulary is not enough. Instead they should be taught how to retain the vocabulary in context to maximise vocabulary acquisition. In order to accomplish this, the retention strategies become central and have a paramount implication on language learning later. In this study, the 25 participants were Year 1 ESL students from a Chinese National-type primary school. These targeted students had problems recognising and retaining the words they had previously learnt. To cater to the problem, an interactive storyboard game (ISG) was devised by taking into account the lack of vocabulary which has caused students to feel inferior in learning English which will bring significant impact to the learners as a whole. Henceforth, this paper illustrates how the interactive storyboard game (ISG), particularly, can be utilised to enhance vocabulary retention through the game devised despite its motivational drive to learners compared to conventional teaching methods.

The aim of the study is to explore the effectiveness of Interactive Storyboard Game (ISG) in aiding pupils to retain the vocabulary that they have been exposed to as well as the effectiveness of ISG in helping pupils to retain vocabulary over a short period of time.

\section{Literature Review Vocabulary}

Chitravelu, Sithamparam \& Teh (2005) define vocabulary as the lexical items in any language that forms the building blocks that make up its vocabulary. Vocabulary is a key element in achieving language mastery because it sets the stage for how successful learners are in acquiring listening, speaking, reading and writing skills (Mashhadi \& Jamalifar, 2015). As a second language learner in an ESL classroom, students often experience the vocabularylearning problem of remembering English words which also reflects that proficiency in English language depends on the knowledge of the vocabulary constructed by the second language learners. Wilkins (1972) points out that not much can be relayed when grammar is lacking, but nothing can be relayed without the building blocks of a language, i.e. its vocabulary. Vocabulary has indeed played a significant role especially among young learners, however the 
vocabulary retention particularly among the lower primary pupils on the ground is often neglected due to a lack of a profound vocabulary-learning strategy. Though learning and expanding vocabulary banks is significant, the problem of vocabulary retention should not be overlooked among lower primary students. There are many factors that influence vocabulary development in learners and among them are how the words change when certain grammar rules are imposed and words with similar meanings as well as the circumstances in which the word is applied. Much research has proven that active learning of vocabulary is more likely to be retained as compared to words that have simply been seen or heard.

On the other hand, previous studies have proven that second language readers greatly depend on the knowledge of vocabulary and the absence of that knowledge happens to be the greatest hurdle for L2 readers to conquer (Huckin, 1997). Despite vocabulary being a a crucial element of any language in the context of communication, it is given minimal emphasis in the teaching and learning process (Lee and Muncie, 2006). Among the reasons stated by Yunus et al (2020) that learners still experience poor vocabulary acquisition is the shortage of media that is able to sustain the learners' interest in vocabulary learning. This will eventually lead to a sharp downturn in learning a language especially among lower primary students if they have limited or poor vocabulary in the second language as this impedes their ability to acquire a second language. Furthermore, a lack of vocabulary also poses a barrier that they must overcome, failing which they may feel demotivated and lose their self-confidence, thereby increasing their affective filter. Therefore, equal importance should be attributed to vocabulary retention to retain the words learnt and integrate retention-based strategies in an ESL context. For this reason, it is vital to understand the importance of vocabulary retention to successfully retain vocabulary in an improved manner. There is an emerging need for teachers to ponder the vocabulary strategy used in improving vocabulary retention among lower primary students as vocabulary retention has become more imperative than ever today. Vocabulary retention can gain its demonstrated superiority in the context of making formal and semantic verbal links with newly known vocabulary, which in other words can lead to better vocabulary learning in the future. For this purpose, the role of vocabulary retention should be ascertained.

In conjunction to vocabulary retention, Hulstijn (1992) revealed that target vocabulary could be retained for a longer period of time if their denotation were accurately deduced than when their similar meanings were explained. This, thereby, indicates that poor retention could lead to poor deciphering of meaning from a comprehension text which causes them to become a struggling reader rather than an active reader. Equally important, Wesche and Paribakht (2000) have also shown that students learned vocabulary more efficiently especially if they are indulged in text-based vocabulary exercises, in addition to reading a text compared than when they read several texts without exercises, and this is because, they could learn not only target vocabulary but also their lexical components. In accordance with this, text-based vocabulary tasks were devised in the interactive storyboard game (ISG) to ensure a positive effect on students' literacy as vocabulary acquisition is complete and effective only when the words learnt are retained.

\section{Interactive Approach}

The advent of the 21st century brought with it many improvements and new suggestions in the field of education, among them new ways of teaching and disseminating knowledge to the learners. In the Malaysian context, this means the use of a more learnercentred curriculum and the incorporation of 21st Century Teaching and Learning which will 
produce learners that are highly competent and capable of making helpful contributions in their respective fields in efforts to achieve the national goals (Garba, Byabazaire \& Busthami, 2015).

Meanwhile, the interactive approach employed in the interactive storyboard game (ISG) has indeed many beneficial abilities to engage and stimulate learning because it is more student-centred compared to conventional teaching methods. The interactive storyboard game (ISG) can be utilised to assess how well students can manipulate a given subject material in vocabulary retention as well as to establish measurable students' accomplishments. Interactive instructions developed by the interactive storyboard game (ISG) could involve students in two-way communications which can enhance the learning process and to increase student motivation to retain the vocabulary learnt. Student motivation can be better instilled when there is two-way teaching which can dispel student passivity. This is because the interactive storyboard game (ISG) promotes the elements of questions that stimulate response, thinking skills and a hands-on experience. Not only does the interactive storyboard game (ISG) help students to explore the visual enhancement for vocabulary retention, but also capture students' attention in reasoning for their answers during the game. The applicability of the interactive storyboard game (ISG) is illustrated when it puts forward a retention strategy to engage students in meaningful vocabulary acquisition through interactive approach developed by the medium, storyboard using Microsoft PowerPoint which utilises content from the CEFR-aligned textbook, to improve the vocabulary of the learners through incorporation of a storyline.

Interactive games and teacher-created games are significantly practical in reinforcing students' understanding and gearing up enthusiasm for learning new words (Blachowicz \& Fisher 2002). In addition, Stanford University School of Medicine highlighted that interactive learning actively indulges the students in handling the material and it helps to re-energise the classroom for students and faculty. Interactive learning is a hands-on approach to optimising learning for students in order to become more involved and therefore retain more materials. Interactive learning, with or without a form of technology, could enable students to strengthen their problem-solving and thinking skills. In fact, the interactive storyboard game (ISG) highlights learning how to solve real problems, involving real people for instance. In addition to that, Comighud, Futalan \& Pillado $(2020$, p.8) ascertain that updated teaching techniques supports inclusive education, which in turn, enhances students motivation and thereby improves memory retention. Students then feel as though they are provided support in the ways in which they are familiar and feel a greater motivation to learn and be included in the lesson.

The visual information enables users to quickly get an overall insight of the domain, facilitate teaching, and find relevant work grounded by various categories identified in a survey taxonomy (Kucher \& Kerren 2015). The pictures that are adapted in the storyboard aid as a visual enhancement for fostering students to better retain the vocabulary from time to time through emphasis as well as trial and error. They can help learners remember vocabulary better, because our brain consciousness of objects and images is very reliable and visual techniques can perform as a reminder of words (Takač, 2008). Also, using pictures as image cues during the interactive storyboard game (ISG) can help students to better comprehend the meaning of a word by decoding a series of images which is primarily used to help students think of what the pictures signify.

From the above review of literature, it is evident that many studies have been carried out focusing on learning new vocabularies through task-based, reading, composition and 
identifying the meanings in its context. But none have discussed the retention strategies and incorporating those strategies in the curriculum. Hence, this study focuses on the application of the retention strategy promoted by integrating the use of interactive storyboard game (ISG) in an ESL classroom to improve vocabulary retention.

\section{Vocabulary Retention}

Vocabulary retention, which is also known as the ability to remember lexical items once a period of time has lapsed (Richards \& Schmidt, 2002, p. 457), is crucial in the mastery of vocabulary. According to Ramezanali (2017), a fortnight following the intervention is believed to be the long-term word retention. This further explains that constantly repeating and meaningful exposure to the lexical items that have been learnt are significant in promoting the students' understanding and memory (Nation, 2001; Schmitt, 2008).

Hopkins et al (2018) claim that the more frequently a piece of information is retrieved from memory, the higher its chance to be remembered over a long period of time. They continue by stating that an increased period of time between retrievals increases long-term retention, up to $80 \%$. One method to increase long-term memory retention is by applying a method called retrieval practice (Hopkins et al., 2018). It is proven by work from Hopkins et al (2018) that long -term memory of a learner can be improved by utilising the right technique. According to Chai Kar Ni et al. (2020, p. 147), games are a viable method to aid learners to retain and utilise new vocabulary in a more efficient manner. Games that incorporate Information, Communication and Technology (ICT) was claimed to be a more effective teaching method than the traditional chalk and talk method due to the fact that learners are more focussed during the fun and relaxing atmosphere (Hashim, Rafiq \& Yunus, 2019)

\section{Methodology \\ Research Design}

This study employed Kemmis and McTaggart's Action Research model employing a mixed-method design to accumulate and analyse data. This study employed the explanatory model, which contains quantitative data collection, then followed by qualitative data collection.

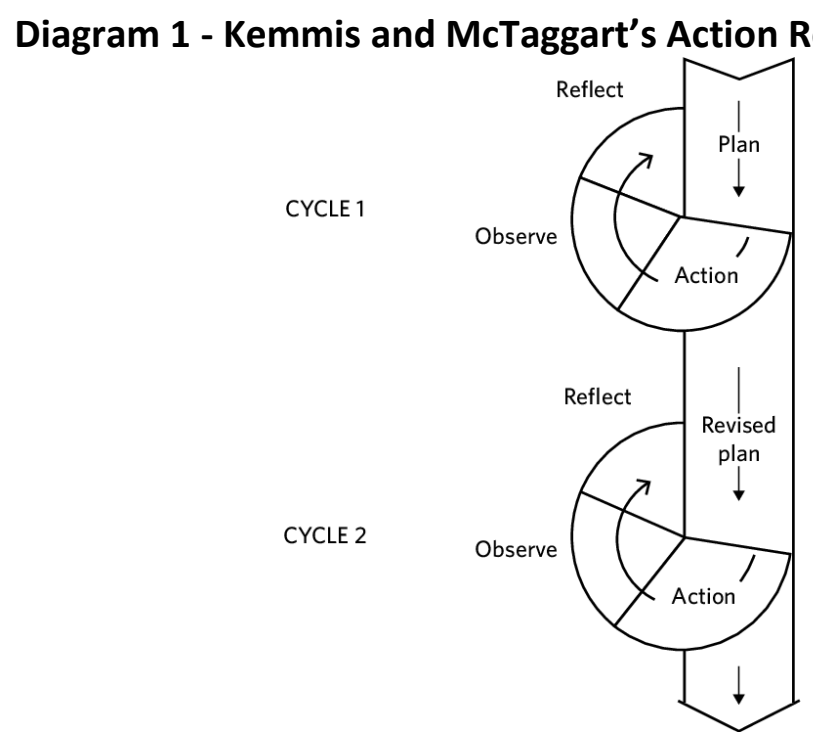

The study was conducted based on the action research model shown above in which we identified the problem that we wished to address, planned our intervention method, carried out the intervention 


\section{Population and Sampling}

The sampling technique used in this project is purposive. The samples of this study were targeted on Year 1 students from a primary school located in Padawan district in the Kuching division of Sarawak. There were a total of 25 samples taken through a purposive sampling method. Respondents were all between 6-7 years of age and from a range of racial groups, including Chinese, Iban and Bidayuh descent.

These respondents are all also English as Second Language learners where most of them speak either Mandarin or Bahasa Melayu as a first language, making the learning of the second language at this age critical to be right.

\section{Instrument}

The instruments used in the data collection procedure were an objective-style pretest as well as post-test, followed by observation notes that would be collected throughout the entire period of the study.

The questions in the pre- and post-tests aimed at determining whether or not respondents possessed knowledge of the particular lexical item. Using a simple objectivestyle pre- and post-test enabled the researcher to focus on the picture-word relationship rather than on other reading skills such as spelling errors. A sample of the instrument used in the pre-test and post-test can be found in Appendix 1 and 2.

Besides the pre- and post-test, the study also utilised observation notes to allow for triangulation of the data collected as well as to increase the validity and reliability of the data obtained.

The data from the pre-test and post-test will be able to determine and answer the research question on the effectiveness of the Interactive Storyboard Game (ISG) in improving the vocabulary retention of the respondents in a quantifiable manner. The observation notes will be coded to identify common themes within the notes themselves.

\section{Data Collection and Analysis}

Data from the pre-test and post-test were collected over a four-week period where respondents were given the pre-test, intervention throughout the 4-week period and finally the post-test. From the pre-test and post-test results, the mean, mode and median as well as the standard deviation of the data was also identified and calculated.

Observation notes were also taken throughout the testing period to be used to identify common themes throughout the entire process.

\section{Findings}

The raw data in diagram 2 reveals that $8 \%$ of respondents showed a deterioration in performance, $8 \%$ remained unchanged while an impressive $84 \%$ of respondents showed a positive improvement in vocabulary retention after the intervention had been implemented over the course of four weeks. 
INTERNATIONAL JOURNAL OF ACADEMIC RESEARCH IN BUSINESS AND SOCIAL SCIENCES Vol. 11, No. 6, 2021, E-ISSN: 2222-6990 @ 2021 HRMARS

Diagram 2 - Score difference obtained by each respondent between the pre-test and posttest

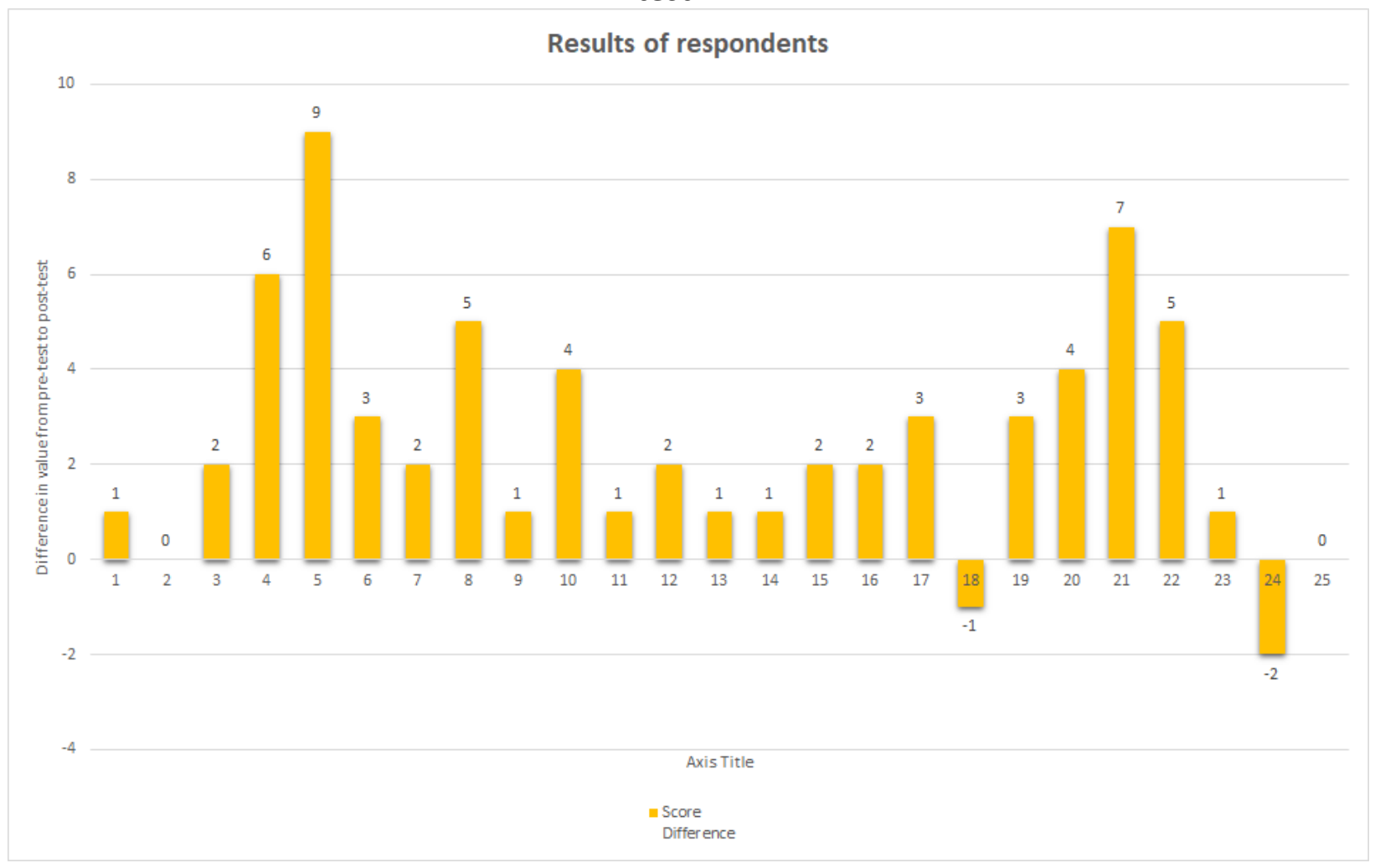


INTERNATIONAL JOURNAL OF ACADEMIC RESEARCH IN BUSINESS AND SOCIAL SCIENCES Vol. 11, No. 6, 2021, E-ISSN: 2222-6990 @ 2021 HRMARS

Table 1 - Frequency of Score Difference, Cumulative Percentage, Variance and Standard Deviation

\begin{tabular}{|c|c|c|c|}
\hline Score Difference & Frequency & Percent & Cumulative Percent \\
\hline-2 & 1 & 4 & 4 \\
\hline-1 & 1 & 4 & 8 \\
\hline 0 & 2 & 8 & 16 \\
\hline 1 & 6 & 24 & 40 \\
\hline 2 & 5 & 20 & 60 \\
\hline 3 & 3 & 12 & 72 \\
\hline 4 & 2 & 8 & 80 \\
\hline 5 & 2 & 8 & 88 \\
\hline 6 & 1 & 4 & 92 \\
\hline 7 & 1 & 4 & 96 \\
\hline 8 & 0 & 0 & 96 \\
\hline 9 & 1 & 4 & 100 \\
\hline Total & 25 & 100 & \\
\hline \multicolumn{2}{|c|}{ Variance: 6.0896} & \multicolumn{2}{|c|}{ Std. dev. $=2.4677$} \\
\hline
\end{tabular}

Table 1 shows the frequency with which each score difference, ranging from a negative value of -2 to a positive value of 9 , was achieved by respondents between the pretest and post-test. The variance value of 6.0896 shows that there is quite a large distance or gap between the average data and the mean, whereas a standard deviation of 2.4677 is also considered to be a fairly wide distribution. This also indicates that $98.65 \%$ of participants were in the normal distribution of data. 


\section{Diagram 3 - Overall Effectiveness of ISG in improving vocabulary retention}

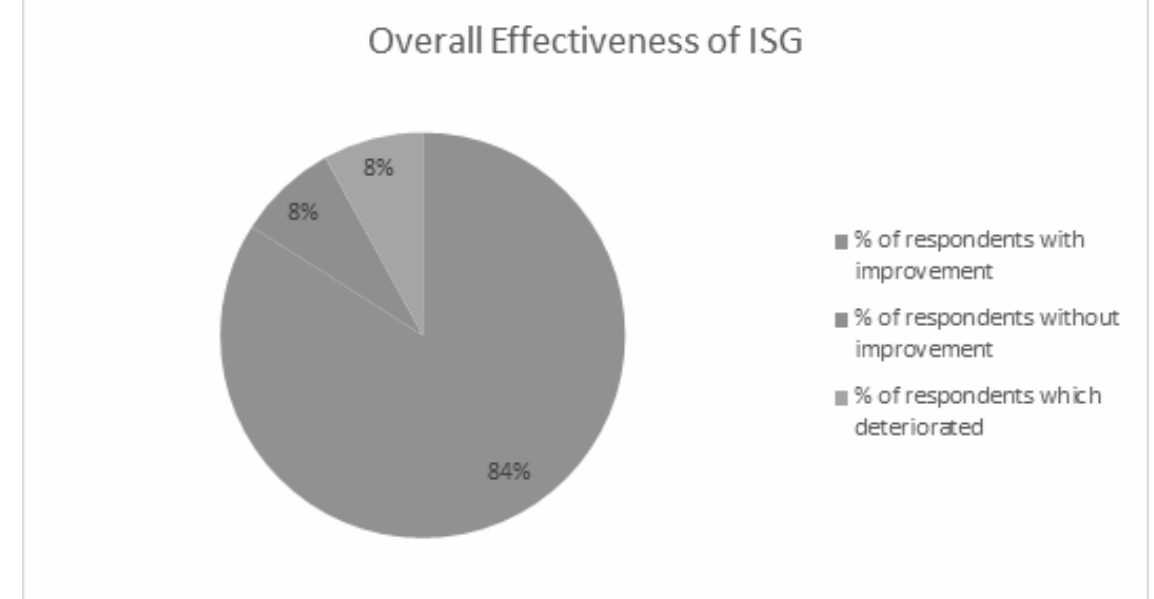

The diagram above shows that ISG was effective at a rate of $84 \%$, equivalent to 21 respondents, while 4 respondents, or a total of $16 \%$ of respondents, showing either none or negative improvement in vocabulary retention. This could be due to the different learning styles of the respondents where some respondents prefer other methods of learning than by games.

\section{Observation}

Based on the observation notes, two main recurring themes were identified as is shown in table 2 below:

Table 2 - Codes based on themes identified in the observation notes

\begin{tabular}{|c|c|}
\hline Codes & Themes \\
\hline A & Issue \\
\hline B & Effectiveness of ISG \\
\hline
\end{tabular}

Alphabetical codes were assigned to the themes identified in the observation notes and these themes have been summarised as in the table above. The themes that have been identified are able to justify the choice of topic and answer the research questions posed earlier. The most often recurring issue identified before the intervention was the difficulty pupils faced in remembering what had been taught in the classroom as they were exposed to a syllabus and content that were somewhat native to them. Having not learnt English as a first language, and some not even as a second language, it is common for pupils to have a very high affective filter in the form of anxiety or fear of failure as well as a lack of motivation and self-confidence.

The second theme was the effectiveness of ISG in aiding the respondents to improve their vocabulary retention and this was identified through casual conversations with the respondents outside of class times, for example early in the morning or during recess. It was found out that many of the respondents themselves felt that they were better able to recall the words learnt after having been taught using the ISG as compared to earlier and previous methods. 


\section{Discussion}

Based on the data in table 1 and 2, it can be deduced that ISG was indeed effective for most of the participants in improving vocabulary retention. As the intervention involved the use of a game, it shows that the interactive game was able to improve the vocabulary of the learners as suggested by Shabaneh \& Farrah, 2019 by allowing respondents to be creative in producing responses and more confident in their abilities to produce the language. The ISG, being an approach that advocates active learning on the part of the students, certainly was able to support the respondents in forming associations between new concepts, i.e. new vocabulary, and existing ideas, i.e. present knowledge, to allow respondents to obtain improved understanding.

Diagram 3 shows that $84 \%$ of respondents showed some improvement throughout the four-week period and this could imply that despite games-based learning being able to promote an atmosphere of fun learning while also motivating pupils in the classroom, not all pupils feel the need to use such methods to accomplish their goals. This relates to Howard Gardner's Theory of Multiple Intelligence that all humans possess. According to Paraiso, 2020, Gardner's Theory claims that our human differences are rooted in the different combinations of intelligences possessed by each individual, which accounts for the fact that games-based learning is not for everyone. This is further supported by research conducted by Pérez et al., 2018 who claim that game-based learning was able to increase a child's logical-mathematical, naturalistic and linguistic abilities (or Intelligences) for the areas studied and the use of stories and games also provided increased motivation to the learners in their study. The $16 \%$ of respondents that were unable to show improvement could have been caused by the next factor as discussed below.

Another factor that affected the effectiveness of ISG in improving the vocabulary retention of the respondents was the use of games which effectively reduced the affective filters of respondents, such as motivation and self-confidence, and allowed the game to be made increasingly more meaningful and playful to the respondents (Singh, 2016). The application of a game through ISG was able to reduce the anxiety and fear of failure that most pupils would experience when learning a second language and aids in developing a positive language learning attitude.

From the results of the vocabulary post-test after four-weeks intervention, it could be deduced that ISG did affect the groups' lexical achievement in a positive manner. There is a significant gap in score differences between pre-test and post-test. This indicates that the intervention has a positive impact on the samples. The research question whether interactive storyboard game was successful in stimulating sample's vocabulary retention has been answered by the post-test conducted as stated above. It can be inferred that interactive storyboard game (ISG) is an effective tool to improve ESL vocabulary. This is so as ISG has a strong possibility of delivering outcomes because of its capacity to increase theoretical pedagogy that will contribute to progress in learning. In a conventional classroom, memorisation of vocabulary tends to construct a barrier for pupils to develop their higher order thinking skill. It is indeed opposing the practice of today's $21^{\text {st }}$ century learning skill. As suggested by (Barron 2008) to enhance high level thinking, students need to engage in complex and meaningful projects that require collaboration, research, resource management, and ambitious performance or product development.

According to Vygotsky's (1978) scaffolding, a teacher can provide support to students through the use of teaching tools, resources and exercises when needed. Support is gradually 
phased out when the pupils have seemed to master the vocabulary. In this research, interactive storyboard game (ISG) serves as an enrichment tool to engage the pupils in learning the targeted vocabulary during the Year 1 English language lesson. All the targeted vocabulary were selected from Supermind Year 1 textbook under the CEFR curriculum specification. Each vocabulary came with a situational scene along with visualisation exercises with lively stories for pupils to comprehend the meaning of learnt vocabulary in context. During the course of the lesson, the teacher would spell out the word, and the pupils would listen. Later pupils were asked to spell out the word on their own. Finally, they could get a chance to participate in the game at the end of each situational scene with the teacher facilitating the process. The whole process was indeed scaffolded under teacher's supervision and pupils learned to become more autonomous learners at the end of the lesson. Consequently, pupils showed better vocabulary retention for word forms, word meaning and word use as ISG activities had positively affected how the lower primary pupils' gain their perceptions towards their mastery of vocabulary. They found it more engaging and inspiring to learn vocabulary with the support of an interactive story in relation to their vocabulary attainment and retention ability of spelling words, word meaning and word use in context.

\section{Conclusion}

The study was able to identify the effectiveness of the Interactive Storyboard Game (ISG) in aiding the respondents to have better vocabulary retention after the intervention had been implemented. Analysis of various approaches and theories to improving vocabulary retention had been discussed and some had been adapted to be used in the ESL context of Malaysia. Games are indeed able to motivate learners and create a fun learning atmosphere which enables learners to become more confident and creative in a real-life context while being effective communicators.

\section{References}

Bakhsh, S. A. (2016). Using Games as a Tool in Teaching Vocabulary to Young Learners. English Langauge Teaching, 9(7)

Barron, B., and Hammond, L. D. (2008). Teaching for Meaningful Learning: A Review of Research on Inquiry-Based and Cooperative Learning, The George Lucas Educational Fundation.

Blachowicz, C. L., and Fisher, P. (2015). Teaching vocabulary in all classrooms. Boston: Pearson.

Garba, S. A., Byabazaire, Y., and Busthami, A. H. (2015). Toward the Use of 21st Century Teaching-Learning Approaches: The Trend of Development in Malaysian Schools within the Context of Asia Pacific. International Journal of Emerging Technologies in Learning, 10(4), 72-79. http://dx.doi.org/10.3991/ijet.v10i4.4717

Hashim, H., Karmila, M. R., and Yunus, M. M. (2019). Improving ESL Learners' Grammar with Gamified-Learning. Arab World English Journal, 5(5), 41-50. https://doi.org/10.24093/awej/call5.4

Hopkins, R., Lyle, K. B., Ralston, P., Bego, C., and Hieb, J. L. (2018). Board 121: Retrieval Practice and Spacing: Effects on Long-Term Learning among Engineering Precalculus Students.

Huckin, T. (Eds.). (1997). Second language vocabulary acquisition. Cambridge: Cambridge University Press. 
Hulstijn, J. H. (1992). Retention of inferred and given word meanings: Experiments in incidental vocabulary learning. In P.J. Arnaud and H. Bejoint (Eds.), Vocabulary and applied linguistics (pp. 113-125). London: Macmillan.

Kucher, K., Kerren, A. (2015) Text visualization techniques: taxonomy, visual survey, and community insights. In: 2015 IEEE Pacific visualization symposium (pacificVis), pp 117121.

Lee, S. H., and Muncie, J. (2006). From receptive to productive: Improving ESL learners' use of vocabulary in a post-reading composition task. TESOL Quarterly, 40, 295-320.

Mashhadi, F., and Jamalifar, G. (2015). Second Language Vocabulary Learning Through Visual and Textual Representation. Procedia - Social and Behavioral Sciences, 192, 298-307. https://doi.org/10.1016/j.sbspro.2015.06.043

Nation, P. (2001). Learning vocabulary in another language. New York: Cambridge University Press.

Paraiso, L. R. (2020). Multi-Modal Meaning: Connecting Multiple Intelligences To Learning Games. ELearning Industry. Retrieved on 29 November 2020 from https://elearningindustry.com/multimodal -meaning-connecting-multipleintelligences-to- learning-games

Pérez, M. E. D. M., Duque, A. P. G., and García, L. C. F. (2018). Game-Based Learning: Increasing the Logical-Mathematical, Naturalistic, and Linguistic Learning Levels of Primary School Students. Journal of New Approaches in Educational Research, 7(1), 31-39. https://doi.org/10.7821/naer.2018.1.248

Ramezanali, N. (2017). Short and long-term vocabulary learning retention through multimedia glossing: A mixed methods research. Electronic Thesis and Dissertation Repository, 4588.

Read, J. (2004). Research in teaching vocabulary. Annual Review of Applied Linguistics, 24, 146-161.

Richards, J. C., and Schmidt, R. (2002). Longman dictionary of language teaching and applied linguistics (3rd Ed.). London: Pearson Education.

Schmitt, N. (2008). Review article: Instructed second language vocabulary learning. Language Teaching Research, 12, 329-363.

Shabaneh, Y., and Farrah, M. (2019). The Effect of Games on Vocabulary Retention. Indonesian Journal of Learning and Instruction, 2(1), 79-90. https://doi.org/10.25134/ijli.v2i01.1687

Singh, S. (2016). Game Based Language Learning in ESL Classroom: A Theoretical Perspective. ELT Vibes - International E-Journal for Research in English, 2, 20-34

Takač, V. P., and Singleton, D. (Eds.) (2008). Vocabulary learning strategies and foreign language acquisition.Canada: Multilingual Matters Ltd.

Wesche, M. B., and Paribakht, T. S. (2000). Reading-based exercises in second language vocabulary learning: An introspective study. Modern Language Journal, 84, 196-213.

Wilkins, D. (1972). Linguistics in Language Teaching. Suffolk: The Chaucer Press.

Yunus, M. M., Lau Yen Yen, E., Khair, H. M. A., and Yusof, M. N. (2020). Acquisition of Vocabulary in Primary Schools Via GoPic with QR Code. International Journal of English Language and Literature Studies, 9(3), 121-131. https://doi.org/10.18488/journal.23.2020.93.121.131 